\title{
Parental Military Service, Agent Orange Exposure, and the Risk of Rhabdomyosarcoma in Offspring
}

\author{
Seymour Grufferman, MD, DrPH ${ }^{1}$, Philip J. Lupo, PhD, MPH${ }^{2}$, Rachel Isaksson Vogel, $\mathrm{MS}^{3}$, Heather E. Danysh, MHS ${ }^{2}$, \\ Erik B. Erhardt, $\mathrm{PhD}^{4}$, and Simona Ognjanovic, $\mathrm{PhD}^{5}$
}

Objective To evaluate the role of parental military service-related exposures and rhabdomyosarcoma (RMS) risk in offspring using data from a large case-control study of childhood RMS.

Study design Cases $(n=319)$ were enrolled from the third trial run by the Intergroup Rhabdomyosarcoma Study Group. Population-based controls $(n=319)$ were pair-matched to cases on race, sex, and age. Conditional logistic regression was used to evaluate parental military service-related exposures and their associations with childhood RMS by generating aORs and 95\% Cls. Statistical significance was defined as $P<.05$.

Results There were no significant associations between parental military service and childhood RMS. The strongest association was with maternal military service; however, this association was attenuated and did not remain significant after adjusting for covariates $(\mathrm{aOR}=2.75,95 \% \mathrm{Cl} 0.71,10.62)$. An elevated effect estimate was found when assessing paternal exposure to Agent Orange (AO) and childhood RMS but was not statistically significant $(\mathrm{aOR}=1.72,95 \% \mathrm{Cl} 0.55,5.41)$.

Conclusions We found little evidence that parental military service of $A O$ exposure influences the risk of RMS in offspring. These findings are notable in light of the continuing controversies surrounding the intergenerational effects of AO exposure. (J Pediatr 2014;165:1216-21).

habdomyosarcoma (RMS) is a rare, highly malignant tumor of primitive mesenchymal cells that display muscle differentiation, which can occur anywhere in the body. Although RMS is the most common soft tissue sarcoma in children and adolescents $<20$ years of age in the US, there are only about 350 new cases of RMS diagnosed per year. ${ }^{1}$ Because of the rarity of these tumors, relatively little is known about the etiology and epidemiology of childhood RMS. A small percentage of cases ( $5 \%$ ) are associated with mutations in TP53 (Li-Fraumeni syndrome), HRAS (Costello syndrome), and NF1 (neurofibromatosis type 1) genes. ${ }^{2-4}$ Previous reports have identified a few positive associations between potential risk factors and childhood RMS, including prenatal radiograph exposure, ${ }^{5}$ maternal drug use, ${ }^{6}$ advanced maternal age, ${ }^{7}$ large for gestational age at birth, ${ }^{7}$ and birth defects. ${ }^{8}$ However, these associations have largely not been replicated. In addition, parental environmental exposures including paternal smoking, maternal exposure to various chemicals, and diets that include organ meats, have been suggested as potential risk factors for childhood RMS.9-11 Much work remains in identifying novel associations.

During the Vietnam War, US military forces sprayed millions of gallons of Agent Orange (AO) and other herbicides on lands in Vietnam, Laos, and other nearby areas to remove forest cover, destroy crops, and clear vegetation from the perimeters of US bases. $^{12}$ This effort, known as Operation Ranch Hand, lasted from 1962 to 1970 . There is suggestive evidence that the risk of birth defects (specifically spina bifida) is increased among the offspring of US soldiers who were exposed to AO ${ }^{12,13}$ In addition, certain cancers in adulthood, including some soft tissue sarcomas, are associated with military service-related exposure to AO or other herbicides. ${ }^{12}$ However, according to the Committee to Review the Health Effects in Vietnam Veterans of Exposure to Herbicides, there is inadequate or insufficient evidence to determine if there is an association between parental exposure to AO and childhood cancers. ${ }^{12,14}$

Although studies related to parental $\mathrm{AO}$ exposure and cancer in offspring have been largely inconclusive, ${ }^{12,14}$ to our knowledge, there have been no direct assessments of the association between parental military service, $\mathrm{AO}$ exposure, and the risk of RMS in children. Because of lingering questions related to parental AO exposure and childhood cancer, we evaluated these associations in a large casecontrol study of childhood RMS.

$\begin{array}{ll}\text { 2,3,7,8-TCDD } & \text { 2,3,7,8-tetrachlorodibenzo-p-dioxin } \\ \text { 2,4,5-T } & \text { 2,4,5-trichlorophenoxyacetic acid } \\ 2,4-D & \text { 2,4-dichlorophenoxyacetic acid } \\ \text { AO } & \text { Agent Orange } \\ \text { IRS-III } & \text { Intergroup Rhabdomyosarcoma Study } \\ \text { RMS } & \text { Rhabdomyosarcoma }\end{array}$

2,3,7,8-TCDD 2,3,7,8-tetrachlorodibenzo-p-dioxin

2,4,5-T 2,4,5-trichlorophenoxyacetic acid

RMS

Rhabdomyosarcoma
From the ${ }^{1}$ Division of Epidemiology and Biostatistics, Department of Internal Medicine, University of New Mexico, Albuquerque, NM; ${ }^{2}$ Department of Pediatrics, Section of Hematology-Oncology, Texas Children's Cancer Center, Dan L. Duncan Cancer Center, Baylor College of Medicine, Houston, TX; ${ }^{3}$ Masonic Cancer College of Medicine, Houston, TX; ${ }^{3}$ Masonic Cancer
Center, University of Minnesota, Minneapolis, MN; ${ }^{4}$ Department of Mathematics and Statistics, University of New Mexico, Albuquerque, NM; and ${ }^{5}$ Mayo Graduate School, Mayo Clinic, Rochester, MN

Supported by the United States' National Cancer Institute (CA21244, CA24507, CA30318, CA30969, CA29139, and CA13539). S.O. was supported in part by the Children's Cancer Research Fund, Minneapolis, MN. P.L. was supported in part by the Kurt Groten Family Research Scholars Award, Houston, TX. The authors declare no conflicts of interest.

0022-3476/\$ - see front matter. Copyright (๑ 2014 Elsevier Inc. All rights reserved.

http://dx.doi.org/10.1016/.jpeds.2014.08.009 


\section{Methods}

Cases and controls were enrolled in a trial previously coordinated by the Intergroup Rhabdomyosarcoma Study (IRS-III) group. ${ }^{15}$ The details regarding the case-control study have been previously described. ${ }^{5,6,8}$ In summary, the cases were consecutively enrolled in the IRS-III study at the time of their RMS diagnosis from April 1982 to July 1988 and were recruited from 69 hospitals across 46 states and the District of Colombia. Eligibility criteria for study enrollment of cases included being diagnosed with RMS at 20 years of age or younger, speaking English or Spanish, receiving treatment at an institution where Institutional Review Board approval was obtained, having a home telephone, and being a US citizen. Of the 511 patients with childhood RMS enrolled in IRS-III during the study period, 440 cases were eligible for the current study and 351 had completed interviews. Of the 71 ineligible cases, 29 had no home telephone, 9 were not US citizens, 15 were from families that did not speak English or Spanish, and 18 were treated in institutions where the Institutional Review Board did not approve the study. An additional 89 cases did not participate because of parental $(\mathrm{n}=41)$ or physician $(\mathrm{n}=30)$ refusal, and 18 families could not be located. Seventy-three percent $(n=322)$ of eligible cases were interviewed and matched with controls; controls were not identified for the remaining 29 eligible cases with completed interviews, and, therefore, these cases were excluded from this assessment. ${ }^{5,6,8}$ Of those interviewed, 319 eligible cases had available information on parental occupation.

Controls were identified by random-digit dialing during the same period. ${ }^{5,6,8}$ Specifically, the telephone area code and first 5 digits of the cases' phone number were used with 2 randomly selected terminal digits to search for matching controls. Controls were matched to cases on race, sex, and age (within 1 year for cases aged $0-5$ years at diagnosis, and within 3 years for cases aged 5-20 years at diagnosis). Twenty-two percent of homes with a matching child refused to participate, and controls could not be identified for $8 \%$ of cases. ${ }^{5,6,8}$

The Institutional Review Board at the Baylor College of Medicine approved this study. Informed consent was obtained from the parents or guardians of each of the case and control children.

Data were collected from case and control families by telephone interview using a structured questionnaire. The child's mother and father were asked to participate in the interview, which for case and control families lasted on average 70 and 68 minutes, respectively. Interviews were conducted in English and Spanish (6 case families and 2 control families were Spanish-speaking). The interview included questions about childhood environmental exposures, parental occupational exposures, family demographic characteristics, parental lifestyle and behavioral characteristics, and medical history. On average, parents were asked to recall exposures that occurred 8-9 years prior to the interview. The questions pertaining to military service, however, focused on the period of the Vietnam War (9-25 years prior to the interview). Each parent was asked if he/she ever served in the armed forces before the date of the index child's diagnosis and, if so, to specify between which years the service occurred. Each parent was also asked if he/she was in contact with nuclear, chemical, and biological weaponry, radiation, radar or microwaves, or AO.

Covariates for this analysis were selected a priori and included total annual household income (categorized as $<\$ 20000, \$ 20000-\$ 39999, \geq \$ 40000)$; length of pregnancy (categorized as preterm, term, or post-term); maternal spotting, cramping, or abnormal bleeding during index pregnancy (yes or no); maternal and paternal educational level (total number of completed years); and recreational drug use during the year prior to index child's birth (yes or no). All statistical models were adjusted for these covariates as well as the matching factors including the child's sex (male or female), age at diagnosis (in years), and race (categorized as White, Black, or other).

\section{Statistical Analyses}

Descriptive statistics were used to characterize the demographic variables among the case and control groups. Frequency distributions were tabulated for categorical variables, and means and SDs were calculated for continuous variables. Univariable regression models were used to evaluate differences in potential confounders, including demographic and pregnancy-related characteristics, between cases and controls; statistical significance was tested using $\chi^{2}$ tests for categorical variables and 2 -sided $t$ tests for continuous variables. Conditional logistic regression was used to evaluate parental military service and service-related exposures and their associations with childhood RMS by generating aORs, 95\% CIs, and $P$ values. An association was considered statistically significant if $P<.05$. Military service-related chemical exposures were included only if they occurred prior to the child's birth and included AO, radiation, radar or microwaves, nuclear weaponry, chemical weaponry, or biological weaponry. All analyses were performed using SAS v 9.2 (SAS Institute, Cary, North Carolina).

\section{Results}

There were 319 patients with RMS and 319 pair-matched controls available for the present analysis. Demographic and pregnancy-related characteristics of patients with RMS and controls are presented in Table I. Patients with RMS and controls were largely similar on demographic characteristics, other than total annual family income, for which a significantly higher proportion of case families were in the lowest income category $(32.8 \%$ of cases vs $23.9 \%$ of controls, $P=.02$ ). Cases and controls did differ on pregnancy-related characteristics including: (1) length of pregnancy (preterm births were more 


\begin{tabular}{|c|c|c|c|}
\hline Variables & $\begin{array}{c}\text { Cases } \\
\mathrm{N}=319\end{array}$ & $\begin{array}{l}\text { Controls } \\
\mathrm{N}=319\end{array}$ & $P$ value \\
\hline \multicolumn{4}{|l|}{ Sex of child, $N(\%)$} \\
\hline Male & $214(67.1)$ & $214(67.1)$ & \multirow[t]{2}{*}{1.00} \\
\hline Female & $105(32.9)$ & $105(32.9)$ & \\
\hline \multicolumn{4}{|l|}{ Race of child, $\mathrm{N}(\%)$} \\
\hline White & $284(89.0)$ & $288(90.3)$ & \multirow[t]{3}{*}{.29} \\
\hline Black & $20(6.3)$ & $21(6.6)$ & \\
\hline Other & $15(4.7)$ & $10(3.1)$ & \\
\hline \multicolumn{4}{|l|}{ Mother's educational level, N (\%) } \\
\hline Less than high school & $45(14.1)$ & $38(12.0)$ & \multirow[t]{3}{*}{.52} \\
\hline High school & $132(41.4)$ & $126(39.7)$ & \\
\hline More than high school & $142(44.5)$ & $153(48.3)$ & \\
\hline \multicolumn{4}{|l|}{ Father's educational level, N (\%) } \\
\hline Less than high school & $54(17.1)$ & $36(11.6)$ & \multirow[t]{3}{*}{.11} \\
\hline High school & $112(35.3)$ & $111(35.8)$ & \\
\hline More than high school & $151(47.6)$ & $163(52.6)$ & \\
\hline \multicolumn{3}{|l|}{ Total annual family income in US dollars, $\mathrm{N}(\%)$} & \multirow[t]{4}{*}{.02} \\
\hline$<\$ 20000$ & $103(32.8)$ & $75(23.9)$ & \\
\hline$\$ 20000-\$ 39999$ & $129(41.1)$ & $154(49.0)$ & \\
\hline$>\$ 40000$ & $82(26.1)$ & $85(27.1)$ & \\
\hline Age at diagnosis/enrollment (y), mean (SD) & $7.6(5.3)$ & $7.5(5.5)$ & .55 \\
\hline \multicolumn{4}{|l|}{ Length of pregnancy, $\mathrm{N}(\%)$} \\
\hline Term & $257(81.3)$ & $255(81.2)$ & \multirow[t]{3}{*}{.004} \\
\hline Preterm & $25(7.9)$ & $9(2.8)$ & \\
\hline Postterm & $34(10.8)$ & $50(15.9)$ & \\
\hline Birth weight (Ib), mean (SD) & $7.4(1.4)$ & $7.5(1.1)$ & .19 \\
\hline \multicolumn{4}{|l|}{ Maternal spotting/cramping/vaginal bleeding, ${ }^{*} \mathrm{~N}(\%)$} \\
\hline Yes & $67(21.1)$ & $37(11.9)$ & \multirow[t]{2}{*}{.003} \\
\hline No & 251 (78.9) & $273(88.1)$ & \\
\hline Number of previous pregnancies, mean (SD) & $3.1(1.6)$ & $3.2(1.6)$ & .63 \\
\hline Number of stillbirths/miscarriages/abortions, mean (SD) & $0.4(0.9)$ & $0.4(0.8)$ & .81 \\
\hline Maternal age (y) at child's birth, mean (SD) & $26.2(5.2)$ & $26.2(5.2)$ & .91 \\
\hline Paternal age (y) at child's birth, mean (SD) & $29.0(5.9)$ & $28.9(6.7)$ & .82 \\
\hline \multicolumn{4}{|l|}{ Maternal recreational drug use, ${ }^{\dagger} \mathrm{N}(\%)$} \\
\hline Yes & $30(9.4)$ & $14(4.4)$ & \multirow[t]{2}{*}{.01} \\
\hline No & $289(90.6)$ & $303(95.6)$ & \\
\hline \multicolumn{4}{|l|}{ Paternal recreational drug use ${ }^{\dagger} \mathrm{N}(\%)$} \\
\hline Yes & $72(22.6)$ & $44(14.1)$ & \multirow[t]{2}{*}{.003} \\
\hline No & 246 (77.4) & 268 (85.9) & \\
\hline
\end{tabular}

common among patients with RMS compared with controls [7.9\% of cases vs $2.8 \%$ of controls, $P=.004]$ ); (2) maternal spotting, cramping, or vaginal bleeding during pregnancy $(21.1 \%$ of cases vs $11.9 \%$ of controls, $P=.003)$; (3) maternal recreational drug use $(9.4 \%$ of cases vs $4.4 \%$ of controls, $P=.01)$; and (4) paternal recreational drug use $(22.6 \%$ of cases vs $14.1 \%$ of controls, $P=.003$ ).

There were no significant associations between parental military service and childhood RMS after adjusting for family income, parental education, recreational drug use, length of pregnancy, and maternal spotting, cramping, or abnormal bleeding during pregnancy (Table II). The strongest association was with maternal military service (crude OR $=3.67,95 \%$ CI 1.02, 13.18); however, this association was attenuated and did not remain significant in the multivariable model $(\mathrm{aOR}=2.75,95 \%$ CI 0.71 , 10.62). Because of the small number of exposed mothers (3.4\% of case mothers and $1.4 \%$ of control mothers), specific time periods could not be evaluated as with fathers. The results remained largely null when evaluating specific paternal service periods including: 1967-1970 (ie, period of peak $\mathrm{AO}$ use, $\mathrm{aOR}=1.01,95 \%$ CI $0.62,1.65$ ); 1967-1970 and within 2 years of child's birth $(\mathrm{aOR}=0.72,95 \%$ CI $0.34,1.52)$; and service in a combat zone during 1962-1973 (ie, Vietnam War, aOR $=1.00$, 95\% CI 0.53, 1.89).

As with paternal military service, military-related exposures among fathers were not significantly associated with the risk of RMS in offspring (Table III). This was true for radiation exposure $(\mathrm{aOR}=0.93,95 \%$ CI $0.27,3.23)$, exposure to nuclear weaponry $(\mathrm{aOR}=0.82,95 \% \mathrm{CI}$ $0.28,2.39)$, and exposure to chemical weaponry $(\mathrm{aOR}=0.97,95 \%$ CI $0.39,2.42)$. Paternal exposure to AO was positively associated with childhood RMS but was not statistically significant $(\mathrm{aOR}=1.72,95 \% \mathrm{CI}$ $0.55,5.41$ ). Paternal exposure to radar or microwaves and paternal exposure to biological weaponry was negatively associated with childhood RMS $(\mathrm{aOR}=0.57$, $95 \%$ CI $0.26,1.26$ and $\mathrm{aOR}=0.30,95 \%$ CI $0.03,3.52$, respectively). However, these findings were not statistically significant. 


\begin{tabular}{|c|c|c|c|c|c|c|c|}
\hline \multirow[b]{2}{*}{ Variables } & \multirow{2}{*}{$\begin{array}{l}\text { No. of case-control } \\
\text { pairs }\end{array}$} & \multicolumn{2}{|c|}{ Cases } & \multicolumn{2}{|c|}{ Controls } & \multirow{2}{*}{$\begin{array}{c}\text { Crude OR } \\
(95 \% \text { CI) }\end{array}$} & \multirow{2}{*}{$\begin{array}{c}\mathrm{aOO} \\
(95 \% \mathrm{Cl}) \\
\end{array}$} \\
\hline & & N & $\%$ & N & $\%$ & & \\
\hline Maternal military service & 295 & & & & & & \\
\hline No & & 285 & 96.6 & 291 & 98.6 & 1.00 (Ref.) & 1.00 (Ref.) \\
\hline Yes & & 10 & 3.4 & 4 & 1.4 & $3.67(1.02,13.18)$ & $2.75(0.71,10.62)$ \\
\hline Paternal military service & 287 & & & & & & \\
\hline No & & 194 & 67.6 & 185 & 64.5 & 1.00 (Ref.) & 1.00 (Ref.) \\
\hline Yes & & 93 & 32.4 & 102 & 35.5 & $0.85(0.60,1.21)$ & $0.85(0.58,1.25)$ \\
\hline Paternal service during 1962-1973 & 287 & & & & & & \\
\hline No & & 225 & 78.4 & 212 & 73.9 & 1.00 (Ref.) & 1.00 (Ref.) \\
\hline Yes & & 62 & 21.6 & 75 & 26.1 & $0.73(0.49,1.08)$ & $0.77(0.50,1.17)$ \\
\hline Paternal service during $1962-1970^{*}$ & 287 & & & & & & \\
\hline No & & 234 & 81.5 & 223 & 77.7 & 1.00 (Ref.) & 1.00 (Ref.) \\
\hline Yes & & 53 & 18.5 & 64 & 22.3 & $0.74(0.49,1.11)$ & $0.78(0.50,1.21)$ \\
\hline Paternal service during $1967-1970^{\dagger}$ & 287 & & & & & & \\
\hline No & & 241 & 84.0 & 240 & 83.6 & 1.00 (Ref.) & 1.00 (Ref.) \\
\hline Yes & & 46 & 16.0 & 47 & 16.4 & $0.95(0.60,1.50)$ & $1.01(0.62,1.65)$ \\
\hline $\begin{array}{l}\text { Paternal service during } 1967-1970^{\dagger} \\
\text { and within } 2 \text { years of child's birth }\end{array}$ & 287 & & & & & & \\
\hline No & & 272 & 94.8 & 268 & 93.4 & 1.00 (Ref.) & 1.00 (Ref.) \\
\hline Yes & & 15 & 5.2 & 19 & 6.6 & $0.81(0.40,1.66)$ & $0.72(0.34,1.52)$ \\
\hline Paternal service in combat zone during $1962-1973$ & 287 & & & & & & \\
\hline No & & 264 & 92.0 & 264 & 92.0 & 1.00 (Ref.) & 1.00 (Ref.) \\
\hline Yes & & 23 & 8.0 & 23 & 8.0 & $1.10(0.62,1.97)$ & $1.00(0.53,1.89)$ \\
\hline
\end{tabular}

Ref., reference.

*Period of $\mathrm{AO}$ use.

†Peak A0 use.

$\ddagger$ Conditional logistic regression with matching factors of age, sex, and race.

$\S$ Maternal military service adjusted for matching factors and family income, maternal education and recreational drug use, length of pregnancy, and maternal spotting/bleeding/cramping during pregnancy.

बPaternal military service variables adjusted matching factors and family income, father's education and recreational drug use, length of pregnancy, and maternal spotting/bleeding/cramping during pregnancy.

\section{Discussion}

Overall, we found little evidence that parental military service or paternal exposure to $\mathrm{AO}$ is associated with RMS in offspring. These findings are based on a large case-control study of childhood RMS to date, with detailed information related to military service and other lifestyle factors that may act as potential confounders. ${ }^{5,611}$ In addition, because cases were diagnosed from April 1982 to July 1988, this was an appropriate study population to evaluate paternal $\mathrm{AO}$ exposure and the risk of childhood RMS, as children diagnosed during this period were conceived during the peak

Table III. Paternal military exposures during the Vietnam War (1962-1973) and childhood RMS

\begin{tabular}{|c|c|c|c|c|c|c|}
\hline \multirow[b]{2}{*}{ Variables } & \multicolumn{2}{|c|}{$\begin{array}{c}\text { Cases } \\
(\mathrm{N}=\mathbf{2 8 7})\end{array}$} & \multicolumn{2}{|c|}{$\begin{array}{c}\text { Controls } \\
(\mathrm{N}=\mathbf{2 8 7})\end{array}$} & \multirow{2}{*}{$\begin{array}{c}\text { Crude } \mathrm{OR}^{\star} \\
(95 \% \mathrm{CI})\end{array}$} & \multirow{2}{*}{$\begin{array}{c}\mathrm{aOR}^{\dagger} \\
(95 \% \mathrm{Cl})\end{array}$} \\
\hline & N & $\%$ & $\mathbf{N}$ & $\%$ & & \\
\hline \multicolumn{7}{|l|}{$\mathrm{AO}$} \\
\hline No & 278 & 98.3 & 282 & 96.9 & 1.00 (Ref.) & 1.00 (Ref.) \\
\hline Yes & 9 & 1.7 & 5 & 3.1 & $2.17(0.75,6.26)$ & $1.72(0.55,5.41)$ \\
\hline \multicolumn{7}{|l|}{ Radiation } \\
\hline No & 281 & 97.9 & 282 & 98.3 & 1.00 (Ref.) & 1.00 (Ref.) \\
\hline Yes & 6 & 2.1 & 5 & 1.7 & $1.29(0.45,3.73)$ & $0.93(0.27,3.23)$ \\
\hline \multicolumn{7}{|c|}{ Radar or microwaves } \\
\hline No & 273 & 95.1 & 268 & 93.4 & 1.00 (Ref.) & 1.00 (Ref.) \\
\hline Yes & 14 & 4.9 & 19 & 6.6 & $0.75(0.37,1.55)$ & $0.57(0.26,1.26)$ \\
\hline \multicolumn{7}{|l|}{ Nuclear weaponry } \\
\hline No & 280 & 97.6 & 279 & 97.2 & 1.00 (Ref.) & 1.00 (Ref.) \\
\hline Yes & 7 & 2.4 & 8 & 2.8 & $0.85(0.31,2.35)$ & $0.82(0.28,2.39)$ \\
\hline \multicolumn{7}{|c|}{ Chemical weaponry } \\
\hline No & 277 & 96.5 & 276 & 96.2 & 1.00 (Ref.) & 1.00 (Ref.) \\
\hline Yes & 10 & 3.5 & 11 & 3.8 & $1.02(0.44,2.36)$ & $0.97(0.39,2.42)$ \\
\hline \multicolumn{7}{|c|}{ Biological weaponry } \\
\hline No & 286 & 99.7 & 285 & 99.3 & 1.00 (Ref.) & 1.00 (Ref.) \\
\hline Yes & 1 & 0.3 & 2 & 0.7 & $0.51(0.05,5.59)$ & $0.30(0.03,3.52)$ \\
\hline
\end{tabular}

${ }^{*}$ Conditional logistic regression with matching factors of age, sex, and race.

†Adjusted for matching factors and family income, father's education and recreational drug use, length of pregnancy, and maternal spotting/bleeding/cramping during pregnancy. 
years of reproduction for those who served in the Vietnam War. ${ }^{12,13}$

From 1962 to 1970, the US military sprayed herbicides over Vietnam to strip the jungle canopy that could conceal opposition forces and to destroy crops that those forces might use for food. These herbicides were largely mixtures of 2,4-dichlorophenoxyacetic acid (2,4-D), 2,4,5trichlorophenoxyacetic acid $(2,4,5-\mathrm{T})$, picloram, and cacodylic acid. The mixtures were named according to the colors of identification bands painted on the storage drums. The main chemical mixture sprayed was AO (a 50:50 mixture of 2,4-D and 2,4,5-T). At the time of the spraying, 2,3,7,8-tetrachlorodibenzo-p-dioxin (2,3,7,8-TCDD), the most toxic form of dioxin, was an unintended contaminant generated during the production of 2,4,5-T and also was present in AO.

The International Agency for Research on Cancer publishes monographs that identify environmental factors that can increase the risk of human cancer. The weight of evidence is evaluated by interdisciplinary working groups of expert scientists who review published studies and, based on the evidence, classify the evaluated agents into 1 of the 5 groups, ranging from "carcinogenic to humans" (group 1) to "probably not carcinogenic to humans" (group 4). Over 900 agents have been evaluated to date, of which 113 have been classified as group 1 , including 2,3,7,8-TCDD. ${ }^{16}$ The $2,3,7,8$-TCDD classification was based on limited evidence in humans and sufficient evidence in experimental animals for the carcinogenicity of this agent. In heavily exposed human populations in which an increased overall cancer risk was observed, tissue concentration of 2,3,7,8-TCDD was similar to the tissue concentration observed in experimental animals exposed to carcinogenic dosage regimens. ${ }^{17}$ However, as the 2,3,7,8TCDD was not the main component, but rather a contaminant of $\mathrm{AO}$, the level of exposure to human carcinogen 2,3,7,8-TCDD in individuals exposed to AO would be difficult to assess. Although animal studies and some epidemiologic studies have pointed to an association between $\mathrm{AO}$ and several adverse outcomes, ${ }^{12}$ studies related to childhood cancer have not been conclusive. ${ }^{12,14,18}$

Our results are consistent with other studies evaluating exposures in Vietnam veterans and the risk of childhood cancer. In the US Centers for Disease Control Vietnam Experience Study, associations between military-related exposures and childhood cancer were not statistically significant $(\mathrm{OR}=1.5,95 \%$ CI $0.7,2.8$ for all cancers and $\mathrm{OR}=1.6,95 \%$ CI $0.6,4.0$ for leukemia). ${ }^{12}$ This was also true for the risk of having a child with acute myeloid leukemia among Australian Vietnam veterans ( $\mathrm{OR}=1.3,95 \%$ CI 0.8, 4.0). ${ }^{18}$ These results and others led the Committee to Review the Health Effects in Vietnam Veterans of Exposure to Herbicides to conclude there is inadequate or insufficient evidence to determine whether there is an association between $\mathrm{AO}$ exposure and childhood cancers. However, the concern related to outcomes in children of those exposed to $\mathrm{AO}$ remains, because $\mathrm{AO}$ contained the carcinogen $2,3,7,8-\mathrm{TCDD}$ as a contaminant, which drives the need for studies evaluating the association between $\mathrm{AO}$ and specific childhood cancers. ${ }^{12}$

Our study must be considered in light of certain limitations. As with any case-control study, there is the potential for recall bias. In this case, parents of children with cancer may be more likely to report exposures differentially compared with control parents. It is impossible to know if recall bias influenced the results reported here; however, our findings are consistent with other studies ${ }^{12,14,18}$ and there is evidence that prompted occupational exposure questions are less likely to be subject to recall bias. ${ }^{19}$ In addition, the prevalence of military service in our sample is similar to that of the US general population at the time of the Vietnam War. ${ }^{20} \mathrm{~A}$ second limitation is that although there is a positive but not statistically significant association between paternal $\mathrm{AO}$ exposure and childhood RMS risk, it is possible that some military workers may have been exposed to AO unknowingly. This potential measurement error may have biased this association toward the null, resulting in inconclusive findings. Another potential limitation is related to the sample size and prevalence of the exposures that were evaluated. In the unadjusted analyses, maternal military service had a strong positive association with RMS in offspring, but this association does not remain statistically significant in the adjusted model. It is possible that history of maternal military service may be important for childhood RMS risk, yet the small sample size may have limited our statistical power after adjusting for relevant covariates as well as our ability to assess maternal service-related exposures in greater detail. An additional limitation is that information on participant response rates by region of the US is unavailable. Nevertheless, cases were enrolled from nearly every state in the US and random-digit dialing methods targeted control subjects residing in the same geographical areas as their matched cases by using the same area code and first five digits of the case's home telephone number. Therefore, because of cases and controls being matched on residential region, it is unlikely that there is substantial bias related to residential region in our assessment. Lastly, demographic information on the children who refused to participate in this study was unavailable for this assessment, and, thus, any differences between those who refused to participate and the subjects included in our assessment could not be assessed. Nevertheless, the participation response rate was relatively high for both cases (92\%) and controls (78\%), and is comparable with other studies conducted during the same period utilizing similar random-digit dialing methods for control group selection. ${ }^{21}$

In conclusion, in this study evaluating parental military service, we found little evidence that $\mathrm{AO}$ exposure and RMS in offspring influenced disease risk. In fact, there were no statistically significant findings in relation to parental military service or service-related exposures and the risk of RMS in offspring. This is an important finding in light of the continuing controversies surrounding AO. As little is known about the etiology of childhood RMS, further studies are needed to discover novel associations. Identifying risk factors for childhood RMS and furthering our understanding of the 
etiologies behind childhood RMS may inform future prevention strategies.

Submitted for publication Mar 21, 2014; last revision received Jul 15, 2014; accepted Aug 7, 2014.

Reprint requests: Philip J. Lupo, PhD, MPH, Department of Pediatrics, Section of Hematology-Oncology, Texas Children's Cancer Center, Dan L. Duncan Cancer Center, Baylor College of Medicine, One Baylor Plaza, MS: BCM305, Houston, TX 77030. E-mail: Philip.Lupo@bcm.edu

\section{References}

1. Hawkins DS, Spunt SL, Skapek SX. Children's Oncology Group's 2013 blueprint for research: Soft tissue sarcomas. Pediatr Blood Cancer 2013;60:1001-8.

2. Hartley AL, Birch JM, Marsden HB, Harris M, Blair V. Neurofibromatosis in children with soft tissue sarcoma. Pediatr Hematol Oncol 1988;5:7-16.

3. Li FP, Fraumeni JF Jr. Soft-tissue sarcomas, breast cancer, and other neoplasms. A familial syndrome? Ann Intern Med 1969;71:747-52.

4. Ognjanovic S, Olivier M, Bergemann TL, Hainaut P. Sarcomas in TP53 germline mutation carriers: a review of the IARC TP53 database. Cancer 2012;118:1387-96.

5. Grufferman S, Ruymann F, Ognjanovic S, Erhardt EB, Maurer HM. Prenatal X-ray exposure and rhabdomyosarcoma in children: a report from the children's oncology group. Cancer Epidemiol Biomarkers Prev 2009; 18:1271-6.

6. Grufferman S, Schwartz AG, Ruymann FB, Maurer HM. Parents' use of cocaine and marijuana and increased risk of rhabdomyosarcoma in their children. Cancer Causes Control 1993;4:217-24.

7. Ognjanovic S, Carozza SE, Chow EJ, Fox EE, Horel S, McLaughlin CC, et al. Birth characteristics and the risk of childhood rhabdomyosarcoma based on histological subtype. Br J Cancer 2010;102:227-31.

8. Yang P, Grufferman S, Khoury MJ, Schwartz AG, Kowalski J, Ruymann FB, et al. Association of childhood rhabdomyosarcoma with neurofibromatosis type I and birth defects. Genet Epidemiol 1995;12:467-74.
9. Grufferman S, Wang HH, DeLong ER, Kimm SY, Delzell ES, Falletta JM. Environmental factors in the etiology of rhabdomyosarcoma in childhood. J Natl Cancer Inst 1982;68:107-13.

10. Hicks N, Zack M, Caldwell GG, Fernbach DJ, Falletta JM. Childhood cancer and occupational radiation exposure in parents. Cancer 1984; 53:1637-43.

11. Lupo PJ, Zhou R, Skapek SX, Hawkins DS, Spector LG, Scheurer ME, et al. Allergies, atopy, immune-related factors and childhood rhabdomyosarcoma: a report from the children's oncology group. Int J Cancer 2014;134:431-6.

12. Institute of Medicine. Veterans and Agent Orange: Update 2010. Washington, D.C.: The National Academies Press; 2012.

13. Ngo AD, Taylor R, Roberts CL. Paternal exposure to Agent Orange and spina bifida: a meta-analysis. Eur J Epidemiol 2010;25:37-44.

14. Ahmad K. Agent Orange no longer linked to childhood AML. Lancet Oncol 2002;3:199.

15. Grufferman S, Delzell E, Delong ER. An approach to conducting epidemiologic research within cooperative clinical trials groups. J Clin Oncol $1984 ; 2: 670-5$.

16. IARC Monographs on the evaluation of carcinogenic risks to humans. Preamble. Lyon: International Agency for Research on Cancer; 2006.

17. IARC Monographs on the evaluation of carcinogenic risks to humansVolume 69. Lyon: International Agency for Research on Cancer; 1997. p. 33-47.

18. Australian Institute of Health and Welfare. Morbidity of Vietnam Veterans. Adrenal Gland Cancer, Leukaemia and non-Hodgkin's Lymphoma: Supplementary Report No. 2; 2001. Canberra: Australian Institute of Health and Welfare.

19. Teschke K, Smith JC, Olshan AF. Evidence of recall bias in volunteered vs prompted responses about occupational exposures. Am J Ind Med 2000; 38:385-8.

20. In U.S., $24 \%$ of Men, $2 \%$ of Women Are Veterans. Gallup; 2012.

21. Bunin GR, Spector LG, Olshan AF, Robison LL, Roesler M, Grufferman S, et al. Secular trends in response rates for controls selected by random digit dialing in childhood cancer studies: a report from the Children's Oncology Group. Am J Epidemiol 2007;166:109-16. 